\title{
O PRAGMATISMO DOS FILÓSOFOS DO CAPITALISMO: UMA EXPERIÊNCIA DIDÁTICA RELACIONADA AO ENSINO-APRENDIZAGEM DA DISCIPLINA FILOSOFIA DA ADMINISTRAÇÃO
}

\section{MANAGEMENT AND KNOWLEDGE IN SOCIAL SCIENCES APPLIED: A TEACHING EXPERIENCE RELATED TO DISCIPLINE OF TEACHING AND LEARNING PHILOSOPHY OF ADMINISTRATION}

\author{
Roberto Bazanini \\ Professor titular do Mestrado em Administração da Universidade Paulista - UNIP \\ São Paulo, SP, Brasil \\ E-mail: roberto.bazanini@terra.com.br \\ Jorge Miklos \\ Professor do Mestrado e Doutorado em Comunicação Social - UNIP \\ São Paulo, SP, Brasil \\ E-mail: jorgemiklos@terra.com.br \\ Homero Leoni Bazanini \\ Doutorando em Comunicação Social pela Universidade Paulista - UNIP \\ São Paulo, SP, Brasil \\ E-mail: homeroleba@uol.com.br \\ Nathalia Caroline Santana \\ Graduanda em administração da Universidade Paulista - UNIP \\ São Paulo, SP, Brasil \\ E-mail: ncs@terra.com.br
}

\section{RESUMO}

O artigo discute alternativas para a construção de alternativas pedagógicas no tratamento de temas transversais no ensino-aprendizagem de filosofia em cursos de gestão dos negócios. Nas pesquisas em administração, inúmeros autores afirmam que a Administração de Empresas deveria ser mais bem entendida mais como uma prática do que como uma ciência, visto que, uma prática é sempre orientada para uma situação de diagnóstico, que se estabelece a partir do momento em que um problema é detectado e precisa ser resolvido. O problema central da pesquisa está em encontrar respostas para a questão: quais conteúdos filosóficos e metodologias podem se tornar adequados para o ensino/aprendizagem de filosofia nos cursos de administração? Por meio de pesquisa exploratória, de natureza qualitativa, análise pós-factum, o objetivo da pesquisa, inicialmente, buscou identificar a percepção dos alunos e professores do curso de administração pertencentes a uma universidade localizada no Grande $A B C$, para posteriormente, submeter os pesquisados ao ensino de filosofia com o emprego da Aprendizagem Baseada em Problemas (ABP) na perspectiva da visão empreendedora. Os resultados da pesquisa apontam a importância do emprego da ABP para dinamizar o conteúdo filosófico como prática executiva dos educandos

Palavras-chave: Empreendedorismo. Ensinoaprendizagem. Filosofia da Administração. Pragmatismo.

\section{ABSTRACT}

The article discusses alternatives to the construction of educational alternatives in the treatment of crosscutting themes in the philosophy of teaching and learning in business management courses. In the research in administration, many authors state that management companies should be better understood more as a practice rather than a science, as a practice is always oriented to a diagnostic situation, which is established from the moment a problem is detected and needs to be resolved. The central research problem is to find answers to the question: what philosophical content and methodologies may become suitable for the teaching / learning philosophy in management courses? According exploratory research, qualitative nature, post-factum analysis, the research objective initially sought to identify the perception of students and teachers of the course of belonging administration to a university in Greater $A B C$, to subsequently submit the respondents to philosophy of teaching with the use of Problem Based Learning (PBL) in connection with the entrepreneurial vision. The survey results point to the importance of the use of BPA to boost philosophical content as executive practice of students.

Keywords: Entrepreneurship. Teaching and learning. Philosophy of Administration. Pragmatism. 


\section{INTRODUÇÃO}

As disciplinas do curso de administração estão voltadas para situações do ambiente interno e externo das organizações (contabilidade, marketing, estatística, economia, etc..) sempre buscando melhorar a eficácia, a harmonia entre os diferentes stakeholders (clientes, colaboradores, fornecedores, governo, etc..), enfim, buscando satisfazer a determinados critérios de desempenho, ou seja, uma prática orientada para uma situação de diagnóstico, que se estabelece a partir do momento em que um problema é detectado e precisa ser resolvido, como explica Lawler, 1985, p. 2).

A pesquisa em comportamento organizacional tem numerosas características que a tornam diferente da pesquisa nas ciências físicas e biológicas. O estudo das organizações e das pessoas que nelas estão é um processo interativo muito mais complexo do que o estudo da maior parte dos fenômenos físicos e biológicos. As pessoas nas organizações não se tornam assuntos no mesmo sentido em que animais, neutrons, e substâncias químicas são assuntos. Essas pessoas constituem uma parte ativa no processo de pesquisa e, como tal, a influenciam muito diretamente. Dada tal diferença, parece bem possível que o que seja uma boa abordagem de pesquisa para contribuir para a teoria e conhecimento científico nos campos tradicionais da ciência possa não ser uma boa abordagem para se trabalhar com organizações.

Historicamente, as organizações se voltam para formar competências, analisar problemas, identificar os pontos fortes e fracos em relação à concorrência, detectar oportunidades e ameaças com o intuito de se alcançar vantagem competitiva.

Particularmente, no curso de administração de empresas, o predomínio da teoria e conhecimento científico faz com que o pensamento filosófico e a atividade de gerenciar negóci se tornem incompatíveis, ou seja, disciplinas estranhas, cujo entrelaçamento com as demais disciplinas do currículo, não oferece nada de útil, pela ausência de pragmatismo.

James (1985), pioneiro do pragmatismo moderno, concebeu o método pragmático como uma atitude, uma orientação, ou seja, a atitude de olhar além das primeiras coisas, dos princípios, das categorias, dos supostos idealismos e de procurar pelas últimas coisas, ou seja, seus frutos, as suas consequências, os fatos.

Por essas razões, é preciso descentralizar o processo de ensino/aprendizagem, redirecionando o saber professoral para o saber social alicerçado na discussão de problemas práticos, como explica Almeida e Alonso (2007, P. 24).

Essa visão do problema sugere que a educação esteja centrada no processo de desenvolvimento humano e implica a potencialização das faculdades pessoais, o desenvolvimento de capacidades e competências necessárias para se enfrentar os desafios da sociedade atual. 
Esse estudo parte da constatação de que nessa situação de dicotomia entre o saber professoral e o saber social, o imaginário em torno da figura do filósofo está associado a suspeita de que a filosofia é uma atividade inútil e incapaz de interessar minimamente aos sujeitos empreendedores. Diante dessas dificuldades decorre o problema central da pesquisa: quais conteúdos filosóficos e metodologias podem se tornar adequados para o ensino/aprendizagem de filosofia nos cursos de administração?

O objetivo da pesquisa está em detectar a percepção dos alunos e professores sobre os conteúdos e metodologias empregadas em sala de aula e, concomitantemente, apresentar uma nova proposta, o ensino de filosofia relacionado à perspectiva da Aprendizagem Significativa (AS) na vertente da Aprendizagem Baseada em Problemas (ABP).

Por meio de pesquisa exploratória, de natureza qualitativa, o instrumento de coleta de dados está voltado para a formulação de questões abertas direcionadas aos professores e alunos dos cursos de administração pertencentes a uma universidade localizada na região do Grande $A B C$, que cursaram a disciplina filosofia com conteúdos e metodologias tradicionais e, posteriormente, com a abordagem da ABP.

Desse modo, o presente trabalho busca resgatar a pertinência do raciocínio filosófico aplicado como prática e, assim, contribuir para se alcançar um melhor entendimento sobre as possibilidades de aplicação de novas metodologias e conteúdos na disciplina filosofia nos cursos relacionados ao universo empresarial.

\section{REVISÃO BIBLIOGRÁFICA}

Acentuadamente, desde a década de 1970, inúmeras publicações sobre os estudos referentes à formação em Administração discorrem criticamente sobre a eficácia do conteúdo ministrado pelas Instituições de Ensino Superior (IES) em todo o Brasil.

Rigby (1965); Clover e Balsley (1974); Emory (1980) concebem que a Administração de Empresas, como ciência social aplicada deveria ser mais vista como uma prática do que como uma ciência, contrariamente as ciências naturais e humanas que buscam o conhecimento como fim último, enquanto que qualquer prática orienta-se para uma situação de diagnóstico. Nesta condição, o grande objetivo da busca do conhecimento nas ciências sociais aplicadas deve estar voltado para a solução de problemas práticos pré existentes.

Particularmente, nas últimas duas décadas surgiram questionamentos e proposições voltadas para as ciências sociais aplicadas no sentido de se elevar o nível de qualidade e metodologias do ensino de graduação dos cursos de gestão dos negócios.

Dentre esses trabalhos pode-se destacar Lopes (2002); Pfeffer, Fong (2004); Moran (2005); Cunha (2006); Vergara (2007); Dutra, Fleury e Ruas (2008); Torre (2008); Veen e Vrakking (2009); Bazanini (2005, 2007, 2010); Knowles, Holton, Swason (2009); Plutarco e Gradvolhl (2010); Masseto (2012); Bazanini e Bazanini (2014), dentre outros.

Lopes (2002) e Vergara (2007) concebem que a baixa qualidade do ensino advém, dentre outras causas, a partir do chamado "Milagre Brasileiro" (1968-1973), período no qual, foram criados cursos de administração em decorrência da atividade industrial de nosso país, da expansão da economia e de mercados, abertura de novas empresas e principalmente pelo estímulo à educação de nível superior decorrente da política governamental das últimas décadas. Pfeffer e Fong (2004) afirmam que a inércia que 
mantém o modelo atual da pesquisa e ensino de administração resulta de atores acomodados e conservadores em posições de comando das instituições tanto públicas quanto privadas. Moran (2005) faz algumas reflexões sobre os novos paradigmas educacionais resultantes da educação on-line; Cunha (2006) discorre sobre as modalidades de ensino que passaram a predominar nos sistemas neoliberais a partir da década de 90; Dutra (2008) aponta as novas tendências da educação na formação de competências para o mercado de trabalho; Torre (2008) discute que as estratégias de ensino não são mais de mera transmissão como ocorrera no passado, mas sim, de interação, motivação, aplicação, investigação, tutoria, resolução de problemas e simulação; Veen e Vrakking (2009) substitui o termo Homo Sapiens por Homo Zappiens, cuja característica dominante está em ser um processador ativo de informação para resolver problemas de modo muito hábil com a utilização de estratégias de jogo acompanhado da capacidade de se comunicar de forma efetiva; Plutarco e Gradvolhl (2010) discorrem principalmente sobre o anacronismo dos métodos, conteúdos, organização e didática que são ainda empregados; Bazanini $(2005,2007,2010)$ na perspectiva do ensino de filosofia como um processo existencial humano afirma que as empresas deveriam ser concebidas como um sistema social, não apenas econômico ou industrial, para uma melhor compreensão de seu funcionamento e eficácia; Knowles, Holton, Swason (2009) acentuam que a educação deveria priorizar a capacidade crítica dos alunos para alcançar resultados práticos por meio do trabalho em equipe. Masseto (2012) discorre sobre as diferentes técnicas de educação que se encontram disponíveis ao educador contemporâneo; Bazanini e Bazanini (2014) buscam distinguir claramente as possibilidades e os fundamentos do conhecimento, a logica da inteligência competitiva e as éticas predominantes no mundo dos negócios.

Regra geral, a crítica central que permeia a pesquisa e ensino em administração nesses autores, diz respeito à dicotomia que se estabelece entre a formação alinhada às demandas de mercados e a criação de condições para formação de cidadãos engajados e conscientes de seu papel político na sociedade. Os críticos advertem sobre o anacronismo das metodologias tradicionais e, concomitantemente, elaboram inúmeras ressalvas sobre o ensino-aprendizagem das disciplinas relacionadas às ciências humanas e sociais, com ênfase nos aspectos da filosofia dissociada da prática social e profissional dos estudantes.

\section{A aprendizagem baseada em problemas (ABP)}

Dentre as abordagens pertencentes a AS, a ABP propõe aos alunos casos simulados ou reais para, inicialmente, serem discutidos de forma teórica e, posteriormente, apresentadas soluções práticas como propostas pedagógicas que permitam aos alunos e professores realizar investigações de caráter básico, socializar conhecimentos, desenvolver competências e atitudes que lhes permitam analisar e discutir criticamente a ciência e suas soluções para os problemas presentes no ambiente.

A ABP é uma proposta pedagógica que começou a ser desenvolvida no final da década de 60 na $\mathrm{Mc}$ Master University (Canadá) e anos depois na Universidade de Maastrich na Holanda.

Essa abordagem consiste em procedimentos inovadores, no qual, situações problemas são apresentadas para iniciar e direcionar a aprendizagem. Autores como Berbel (1998); Barrows e Tamblyn (1980); Bufrem e Sakakima (2003); Ribeiro (2008) Ramos (2010); Pretto e Riccio (2010) Masseto (2012) discorrem sobre os aspectos fundamentais da interaprendizagem, cuja especificidade está em envolver o 
aluno com um todo: idéias, sentimentos, cultura, valores, sociedade, profissão, etc., na qual são valorizadas a autoaprendizagem e a Inter aprendizagem.

Nessa visão pragmática, um dos primeiros percursores dessa proposta foi o filósofo norte-americano John Dewey. Dewey (1959) afirma que para uma sociedade ser efetivamente desenvolvida, deve discutir, sempre, as vantagens e desvantagens de comportamentos ao invés de condenar, à primeira vista, um determinado comportamento. Ao discursar em favor do que pode haver de bom na administração de empresas, enfatiza que preferia que os filósofos agissem menos como padres e mais como advogados e engenheiros, uma vez que, os primeiros, já sabem tudo o que tem de dizer a respeito de todo e qualquer problema, enquanto os segundos, tendo de resolver caso por caso, são obrigados a ouvir, pensar, refletir e solucionar problemas e situações particulares e contingentes.

Desse modo, para a AS, uma nova maneira de fazer sempre traz em si, embrionariamente, novos aspectos do objeto em questão, acompanhado de uma nova forma de conduta.

Uma das afirmações mais controversas para aqueles que raciocinam com base nos preconceitos do senso comum diz respeito à inclusão na categoria de filósofos dos pensadores pró-capitalistas, uma vez que, no ensino tradicional somente se admite no ato de filosofar como próprio daqueles que buscam a sabedoria para além dos interesses mundanos.

Bazanini (2010), ao analisar os operadores básicos das ciências humanas, esclarece que nas ciências sociais aplicadas a definição constitui uma escolha, delimitação do objeto a ser estudado com o intuito de dar um sentido que interessa ao seu autor. Nessa linha de raciocínio, caso se adote a definição tradicional de filosofia concebida como amor à sabedoria, evidentemente, não se justifica a inclusão de executivos voltados para a vantagem e o lucro na condição de filósofos. Contudo, se a definição tradicional for substituída por uma definição pragmática, como por exemplo, filosofia como concepção do mundo da qual se deduz certa forma de conduta, a inclusão dos pensadores das teorias da administração na condição de filósofos do capitalismo se torna pertinente.

Masseto (2012) corrobora com essa visão ao direcionar sua análise para a importância da aplicação dos conhecimentos adquiridos em sala de aula à vida profissional e à solução de problemas alicerçados em competências como criatividade e imaginação.

Assim, ao refletir sobre a melhor maneira de fazer, e ultrapassar o mero empirismo do senso comum que até então, predominava na administração, embrionariamente, as funções de planejar, organizar, dirigir e executar se tornaram imprescindíveis para o sucesso empresarial e. consequentemente, desde o século XVIII, os filósofos do capitalismo como produto da Revolução Industrial, com criatividade e imaginação legaram para o universo do conhecimento a contínua busca da eficiência, dando origem as mais diferentes escolas do pensamento administrativo.

\section{Os Filósofos do Capitalismo}

O pensamento administrativo possui fundamentos filosóficos que precisam ser melhor explicitados como prática para os futuros gestores, visto que, desde os primeiros pensadores voltados para a inteligência competitiva na prática empresarial, os preceitos da AS e as estratégias presentes na metodologia da ABP, mesmo de forma embrionária, sempre estiveram presentes. 
Nesse estudo concebe-se como filósofos do capitalismo, pensadores da administração que, na formulação e implementação de estratégias, buscaram a melhor maneira de fazer para maximizar a produtividade pela elaboração de sistemas até certo ponto complexos (GABOR, 2001).

Nessa perspectiva podem ser considerados como exemplos paradigmáticos, os primeiros pensadores da economia e da administração que forneceram as bases do desenvolvimento gerencial, dentre os quais se podem destacar: Adam Smith; Herbert Spencer (foram principalmente economistas); Frederick Wislom Taylor, Mary Parker Follet, Peter Drucker e Edwards Deming (atuaram principalmente como consultores) e Elton Mayo, Chester Irving Barnard, Douglas Mc Gregor e Abraham Maslow (foram, sobretudo acadêmicos).

Esses primeiros pensadores do universo empresarial, os consultores e acadêmicos forneceram elementos do pensar filosófico para as atividades lucrativas. Pioneiros, como Smith (2003), ao investigar a natureza e as causas da riqueza das nações lançou as bases do liberalismo como os princípios da livre concorrência e o conceito de livre-mercado. Spencer (1939), considerado o fundador do darwinismo social buscou no evolucionismo os mecanismos e objetivos da sociedade, e defendeu o ensino da ciência para formar adultos competitivos por considerar a sociedade como uma "selva concorrencial", na qual somente os mais aptos sobrevivem.

$\mathrm{Na}$ condição de consultores e gestores, Taylor (1990), inspirador do modelo da Administração Científica, um pensador obstinado pelo trabalho eficiência e produtividade, criticou o laissez-faire do empirismo tradicional; Fayol (1987), elaborou princípios básicos da Administração e a departamentalização com base nos organismos biológicos. Follet (s/d) concebeu que somente a identificação com os impulsos sociais subjacentes pode fazer com que os executivos construam grandes organizações;

$\mathrm{Na}$ condição de acadêmicos e gestores, Mayo (1933), inspirador da Escola das Relações Humanas enfatizou a importância da motivação na busca da excelência empresarial; Barnard (1968), escritor e presidente da New Jersey Bell, demonstrou a importância da persuasão retórica do líder para que grandes empreendimentos ocorram, através da teoria da aceitação da autoridade; propiciando uma importante contribuição à Escola Comportamental ao atualizar a Teoria das Relações Humanas; Deming (1997), estatístico norte-americano procurou unir em um único sistema as visões das ciências exatas e das ciências humanas. Formulou e divulgou os princípios da Gestão da Qualidade, que contribuíram para a recuperação econômica do Japão que, posteriormente, se tornou um novo paradigma para a administração no ocidente; Drucker (1993), jornalista que elaborou teoricamente a necessidade da adaptabilidade das organizações modernas ao novo dinamismo social e tecnológico, denominado por ele de Sociedade do Conhecimento. McGregor (1992) sintetizou brilhantemente a atitude da escola clássica, denominando-a Teoria X, teoria essa, absolutamente pessimista em relação à natureza humana comparativamente ao Modelo de Relações Humanas, denominado-a Teoria $\mathrm{Y}$, teoria essa, radicalmente otimista em relação ao ser humano. Maslow (2001) atualiza a teoria $Y$ de McGregor, enunciando uma concepção dinâmica do crescimento pessoal, todavia, não radicalmente otimista como os teóricos defensores da idéia do desenvolvimento humano, reconhecendo os bloqueios inibidores do crescimento.

Em síntese, seja como pioneiros, consultores, gestores e acadêmicos, os pensadores da inteligência competitiva apresentam um repertório de ideias sobre estratégias provenientes dos mais diferentes campos do saber: engenharia, psicologia, sociologia, biologia, permitindo às empresas aplicar as mais recentes 
descobertas científicas e humanísticas de modo pragmático na defesa de seus interesses, por isso, podem ser classificados legitimamente na condição de filósofos do capitalismo.

\section{Alfabetização Metodológica: Definição e Método}

O sucesso do aprendizado em qualquer aspecto da realidade humana está na disposição dos envolvidos em serem submetidos à alfabetização metodológica, como explica Bazanini e Bazanini (2014, p, 14 e 15).

Alfabetizar é aprender a linguagem de determinado ramo do saber. Alfabetização metodológica é o passo inicial para o entendimento de qualquer campo do conhecimento, por isso, a classificação das ciências e a compreensão de seus operadores se tornam essenciais para o entendimento daquilo que se estuda. (...) a alfabetização metodológica objetiva propiciar ao estudante das ciências sociais aplicadas a capacidade de analisar (decompor), sintetizar (unir), assim, perceber a evolução presente no processo de produção do conhecimento decorrentes das mudanças do contexto social.

$\mathrm{Na}$ perspectiva da AS, recomenda-se que, tanto professores quanto estudantes, devem ser submetidos à alfabetização metodológica para o estudo das ciências sociais. Inicialmente, é proposta a necessidade do entendimento de sete operadores básicos (definir, explicar, exemplificar, diferenciar, descrever, narrar e dissertar). Dentre esses operadores, a definição é concebida como o ato de delimitar o objeto de estudo, escolher, propiciar um sentido intencional conveniente aos interesses de seu autor.

Evidentemente, a filosofia pode ser definida de inúmeras maneiras, todavia, para os propósitos do emprego da metodologia da $\mathrm{ABP}$, a definição pragmática de "filosofia como uma visão geral de mundo da qual se deduz certa forma de conduta" permite a formulação de um método adequado a dinâmica do universo empresarial.

E sendo o objetivo central do presente estudo, além de detectar a percepção dos alunos e professores sobre os conteúdos e metodologias empregadas em sala de aula, apresentar uma nova proposta de ensino/aprendizagem da disciplina filosofia voltado para a atividade empresarial, o método escolhido se caracteriza pelo pragmatismo, ou seja, parte-se do pressuposto de que a intencionalidade dos agentes está em alcançar vantagens para si ou para sua organização em ambientes altamente competitivos, conforme quadro 1.

\section{Quadro 1 - Elementos do Método}

\begin{tabular}{|l|}
\hline Primeiro procedimento - Investigar as exigências do contexto social: \\
\hline Segundo procedimento - Relacionar o contexto social ao Processo de Produção do Conhecimento. \\
\hline Terceiro procedimento - Acentuar o Enfoque analítico e crítico. \\
\hline Quarto procedimento - Considerar o sucesso como validação da estratégia empregada. \\
\hline Quinto procedimento - Sintonizar a ideologia do pensamento com o temperamento de seu autor. \\
\hline
\end{tabular}
Fonte: Bazanini (2007, p.68).

Assim, para o efetivo emprego de didáticas compatíveis com o dinamismo das atividades empresariais, a questão do método se torna de fundamental importância para se estabelecer relações de autoaprendizagem e Inter aprendizagem a partir da sala de aula. 


\section{Justificativa dos procedimentos do método}

Os procedimentos do método, pelo seu caráter pragmático, colocam em evidência, as controvérsias, conveniências e críticas presentes na reflexão filosófica desde seus primórdios, conforme Bazanini (2010, p.22): controvérsias - qualquer assunto humano possui no mínimo, duas posições aceitáveis; conveniência o ponto de vista dentro da controvérsia; crítica - um novo ponto de visa sobre a conveniência de alguém.

Para Bazanini (2010, p. 23), a alfabetização metodológica constitui a premissa básica nos estudos de filosofia aplicados às ciências sociais na era tecnológica. Em nossa contemporaneidade, desde o surgimento da INTERNET, a revolução tecnológica está remodelando a base material da sociedade em ritmo acelerado e se "a tecnologia é a sociedade, e a sociedade não pode ser entendida ou representada sem suas ferramentas tecnológicas" (CASTELLS, 2005, p. 25).

Decorre, então, que a investigação do contexto social constitui o ponto de partida do processo educacional, visto que, a sociedade em rede é essencialmente tecnológica e, como ressalta Lemos (2002, p. 147) "hoje, rede significa uma estrutura telemática ligada a conceitos como interatividade, simultaneidade, circulação e tactibilidade".

Desse modo, o grau de desenvolvimento tecnológico presente no contexto social determina a qualidade e o grau de complexidade das relações sociais, consequentemente, os problemas causados pela habilidade ou inabilidade em dominar essas mesmas tecnologias (CASTELLS 2005, p. 26):

(...) sem duvida a habilidade ou inabilidade das sociedades dominarem a tecnologia e, em especial, aquelas tecnologias que são estrategicamente decisivas em cada período histórico, traça seu destino a ponto de podermos dizer que, embora não determine a evolução histórica e a transformação social, a tecnologia (ou sua falta) incorpora a capacidade de transformação das sociedades, bem como os usos que as sociedades, sempre em um processo conflituoso, decidem dar ao seu potencial tecnológico.

Na perspectiva da ABP, o Processo de Produção do Conhecimento está intrinsecamente relacionado às Exigências do Contexto Social, tendo o Enfoque Analítico e Crítico a função de verificar continuamente a adequação do conhecimento proposto ao contexto, sendo que sua pertinência ou não, ocorre por meio de pesquisas que irão ou não confirmar se determinada atitude ainda é pertinente ou não. Comumente, no mundo dos negócios, caso o sucesso seja alcançado determinada estratégia anteriormente empregada é validada, caso contrário, essa atitude será rejeitada como ineficaz e a estratégia não será validada para aquele contexto, pois, como propôs o professor Zaccarelli $(2000,55)$ : "Vale salientar que não existe estratégia certa, existe estratégia que deu certo, assim como não existe estratégia errada, existe estratégia que deu certo".

Evidentemente, esse caráter pragmático das soluções estratégicas recebe influência do próprio Temperamento do Autor, isto é, as pessoas pertencentes ao mesmo contexto social podem propor soluções diferentes para os mesmos problemas em sintonia com as características de sua visão de realidade, na qual estão presentes: crenças valores, grau de conhecimento e atitudes que, subjetivamente, são valorizadas no contexto social. 
Ressalte-se que, ao se partir das exigências do contexto social para se conceber a produção do conhecimento os problemas estão sendo priorizados em consonância com a recomendação de Prado de Mendonça (1984, p.72).

Não bastam teorias. É necessário que saibamos sempre relacioná-las aos problemas a que se referem. É necessário, especialmente, saber colocar os problemas. Não podemos aceitar qualquer problema, colocado de qualquer maneira. Para nós, o valor por excelência de uma verdadeira filosofia é que ela começa pelo debate sobre a maneira correta de se colocar um problema.

Portanto, os cinco procedimentos do método proposto (quadro 1), em consonância com a dinâmica da $\mathrm{ABP}$, em seu conjunto, constituem visão pragmática por excelência das ciências sociais aplicadas, por isso, adequados ao estudo das filosofias implícitas nas diferentes teorias do pensamento administrativo.

\section{PROCEDIMENTOS METODOLÓGICOS}

O percurso metodológico é um conjunto de escolhas que o pesquisador faz para realizar seu estudo. As decisões envolvem o método, a estratégia e as técnicas de coleta, a organização, a análise e a interpretação dos dados (GIGLIO E HERNANDES, 2012, p.81).

Optou-se nessa pesquisa pelo método de investigação qualitativa que envolve "a obtenção de dados descritivos sobre pessoas, lugares e processos interativos pelo contato direto do pesquisador com a situação estudada, procurando compreender os fenômenos segundo a perspectiva dos sujeitos" (GODOY, 1995, p.58).

Nessa pesquisa, a escolha do método qualitativo, ex-post-factum, justifica-se em decorrência da investigação do papel do professor ao ministrar o conteúdo filosófico envolver, sobretudo, interação social (FLICK, 2009, P.20).

Considerando os tipos de pesquisas discutidos na literatura, nesse artigo pretende-se investigar a questão de pesquisa a partir tipologia de pesquisa exploratória, ao qual possui a função de examinar um tema ou problema de investigação pouco estudado ou que não tenha sido abordado antes (SAMPIERI, COLLADO E LUCIO, 1991, p.59). Também porque a pesquisa exploratória é adequada aos propósitos desse artigo devido aos raros estudos que identificaram a importância de se adequar o conteúdo filosófico às teorias da administração.

Quanto à estratégia de pesquisa adotada para a condução dessa investigação, escolheu-se o estudo de caso, que é "uma investigação empírica que indaga os fenômenos contemporâneos dentro de um contexto real, de forma que os limites desse fenômeno e o contexto se confundem" (YIN, 2010).

\section{Seleção da Amostra}

Para se evitar possíveis vieses, tais como; alunos não comprometidos com o curso e professores inexperientes ou sem formação em gestão empresarial, a amostra foi composta de três professores (todos lecionam a disciplina há mais de cinco anos, sendo dois com formação em ciências sociais e economia e 
outro com formação em filosofia e administração) e quarenta alunos que tiveram aproveitamento satisfatório (média acima de sete) nas disciplinas consideradas práticas e que foram reprovados na disciplina Filosofia da Administração, cujo conteúdo ministrado esteve relacionado ao estudo de manuais da história da filosofia e metodologia tradicional e que, posteriormente, ou seja, no primeiro semestre de 2014 , refizeram a disciplina com o conteúdo e metodologia voltado para a ABP, com um dos professores.

Os professores foram entrevistados individualmente com duas questões abertas (quadro 2) enquanto os alunos foram divididos em quatro grupos, com dez componentes, sob liderança de um dos membros, para responder quatro questões abertas (quadro 3).

\section{Quadro 2 - Questões para os professores}

\begin{tabular}{|l|}
\hline 1. O que é ser professor de filosofia no século XXI para os alunos do curso de administração? \\
\hline 2. Qual a principal barreira encontrada no ensino da disciplina filosofia?
\end{tabular}
Fonte: Elaborado pelos autores.

\section{Quadro 3 - Questões para os alunos}

\begin{tabular}{|l|}
\hline 1. Qual a principal barreira encontrada no aprendizado da disciplina filosofia? \\
\hline 2. Como foi a experiência de estudar os teóricos da administração na perspectiva filosófica? \\
\hline 3. Em sua opinião que contribuições esse estudo pode trazer para sua vida acadêmica ou profissional? \\
\hline 4. Cite um exemplo marcante presente nesse aprendizado?
\end{tabular}
Fonte: Elaborado pelos autores.

\section{RESULTADOS DA PESQUISA}

De modo geral, as respostas dos professores ressaltam a importância de se empregar metodologias e ministrar conteúdos que tenham relevância para os alunos e, para tal, é preciso haver comprometimento e atualização didática, tanto temática quanto prática.

Pelas respostas dos entrevistados é possível inferir que o método deve primar pelo pragmatismo relacionado ao saber sociológico, ao mesmo tempo em que o anacronismo do ensino tradicional é criticado (quadros 4, 5, 6, 7 e 8).

\section{Quadro 4 - Respostas dos professores}

\begin{tabular}{|l|}
\hline O que é ser professor de filosofia no século XXI para os alunos do curso de administração? \\
\hline $\begin{array}{l}\text { P1. "É agregar valores à vida e à carreira do aluno, pelo conteúdo (da disciplina ministrada) e encantar pelo método } \\
\text { (forma de abordar o conteúdo e uso de cases)". }\end{array}$ \\
\hline $\begin{array}{l}\text { P2. "É ser um mediador na construção do conhecimento, mas para isso, deve ter algumas competências: ter boa } \\
\text { formação; saber usar novas tecnologias; atualização constante na didática, na temática e na prática". }\end{array}$ \\
\hline $\begin{array}{l}\text { P3. "O professor precisa migrar de educador para facilitador e partir suas abordagens de situações concretas que fazem } \\
\text { parte do repertório de vida dos alunos". }\end{array}$ \\
\hline Qual a principal barreira encontrada no ensino da disciplina filosofia? \\
\hline P1. "A falta de relação do conteúdo da disciplina com a vivência dos alunos nas áreas de administração". \\
\hline P2. "A desatualização do professor aos estilos de aprendizagem demandado pelo alunado". \\
\hline P3. "O aluno vive no século XXI e as técnicas de ensino tradicional de filosofia são do século XIX". \\
\hline
\end{tabular}
Fonte: Elaborado pelos autores. 
As respostas dos alunos enfatizam o desinteresse no aprendizado da disciplina Filosofia baseado nos conteúdos do ensino tradicional destacam a importância de se estudar a filosofia na perspectiva dos filósofos do capitalismo.

\section{Quadro 5 - Respostas dos alunos do Grupo I}

1. Qual a principal barreira encontrada no aprendizado da disciplina filosofia?

R1. Principal barreira: falta de interesse pelo conteúdo ministrado.

2. Como foi a experiência de estudar os teóricos da administração na perspectiva filosófica?

R2. Surpreendente. Jamais se poderia imaginar que o conteúdo filosófico seria compatível com a administração.

3. Em sua opinião que contribuições esse estudo pode trazer para sua vida acadêmica ou profissional?

R3. Aprender a pensar de forma racional e crítica sobre o que é na verdade ser empreendedor.

4. Cite um exemplo marcante presente nesse aprendizado?

R4. Caso SBT versus TV Manchete.

Fonte: Elaborado pelos autores.

\section{Quadro 6 - Respostas dos alunos do Grupo II}

1. Qual a principal barreira encontrada no aprendizado da disciplina filosofia?

R1. Principal barreira: Assuntos sem nexo. Enrolação do professor.

2. Qual a principal barreira encontrada no aprendizado da disciplina filosofia?

R2. Bem diferente. Raciocinar é encontrar soluções aceitáveis pela resolução de problemas.

3. Em sua opinião que contribuições esse estudo pode trazer para sua vida acadêmica ou profissional?

R3. Entender que as disciplinas humanas se voltam para os relacionamentos e complementam os aspectos exatos das demais disciplinas do curso

4. Cite um exemplo marcante presente nesse aprendizado?

R4. As éticas presentes na Doutrina do Interesse do Acionista e a Doutrina da Responsabilidade Social e o depoimento de Taylor na Câmara dos Comuns em 1912.

Fonte: Elaborado pelos autores.

\section{Quadro 7 - Respostas dos alunos do Grupo III}

1. Qual a principal barreira encontrada no aprendizado da disciplina filosofia?

R1. O conteúdo fantasioso da filosofia com afirmações dissociadas do tempo em que estamos vivendo.

2. Como foi a experiência de estudar os teóricos da administração na perspectiva filosófica?

R2. Impactante. Nada tem a ver com aquilo que os livros de filosofia trazem. Nunca tinha ouvido falar de filósofos do capitalismo.

3. Em sua opinião que contribuições esse estudo pode trazer para sua vida acadêmica ou profissional?

R3. A palavra filosofia deve ser mencionada no plural "filosofias".

4. Cite um exemplo marcante presente nesse aprendizado?

R4. Caso SBT versus TV Manchete.

Fonte: Elaborado pelos autores. 


\section{Quadro 8 - Respostas dos alunos do Grupo IV}

\begin{tabular}{l} 
1. Qual a principal barreira encontrada no aprendizado da disciplina filosofia? \\
R1. Um amontoado de informações para se passar o tempo. \\
\hline $\begin{array}{l}\text { 2. Como foi a experiência de estudar os teóricos da administração na perspectiva filosófica? } \\
\text { R2. Motivador. A prática pode ser melhorada pelo conhecimento teórico. }\end{array}$ \\
\hline 3. Em sua opinião que contribuições esse estudo pode trazer para sua vida acadêmica ou profissional? \\
R3. As disciplinas humanas e exatas são complementares e não excludentes. \\
4. Cite um exemplo marcante presente nesse aprendizado? \\
R4. As éticas presentes na Doutrina do Interesse do Acionista e a Doutrina da Responsabilidade Social e o depoimento \\
de Taylor na Câmara dos Comuns em 1912.
\end{tabular}
Fonte: Elaborado pelos autores.

As respostas dos professores e alunos pesquisados, em seu conjunto, remetem a idéia de que o ensino de filosofia para o curso de administração deve partir de questionamentos sobre a vivência cotidiana e que o conhecimento somente se torna relevante se estiver voltado para o campo de atuação dos futuros profissionais, conforme quadro 9.

\section{Quadro 9. Temas pertinentes e respostas dos entrevistados}

\begin{tabular}{|l|l|}
\hline Temas & Respostas dos entrevistados \\
\hline Praticidade do conhecimento & $\begin{array}{l}\text { "O administrador vive no mundo prático e essa forma de } \\
\text { abordagem está bem mais próxima da realidade que vivemos } \\
\text { cotidianamente". }\end{array}$ \\
$\begin{array}{l}\text { A Filosofia como auxiliar do raciocínio para se tomar } \\
\text { decisões. }\end{array}$ & $\begin{array}{l}\text { 2. "Conhecer a história dos administradores antigos favorece a } \\
\text { capacidade de raciocinar para se tomar decisões". }\end{array}$ \\
Exemplos marcantes sobre o conteúdo ministrado. & $\begin{array}{l}\text { "O crescimento da TVS (SBT) e a falência da TV Manchete". } \\
\text { "A visão sobre a complementariedade entre as éticas". } \\
\text { "A relação entre a Doutrina do Interesse do Acionista e a } \\
\text { Doutrina da Responsabilidade Social”. }\end{array}$ \\
\hline
\end{tabular}

Fonte: Elaborado pelos autores com base nas respostas dos entrevistados. 


\section{ANÁLISE DOS RESULTADOS}

Os conteúdos filosóficos nas atividades executivas devem estar voltados para os aspectos pragmáticos e em termos metodológicos para a pesquisa-ação, como ressignificação das espirais cíclicas, como afirma Barbier (2002, p. 117):

(...) que o verdadeiro espírito da pesquisa-ação consiste em sua "abordagem em espiral". Significa que "todo avanço em pesquisa-ação implica o efeito recursivo em função de uma reflexão permanente sobre a ação.

Por essa razão, o método da pesquisa-ação deve contemplar o exercício contínuo de suas diversas etapas, por meio das espirais cíclicas no processo pedagógico intermediário, ou seja, na produção de conhecimento e socialização de saberes.

Assim, as alternativas pedagógicas para o tratamento de temas transversais para a disciplina filosofia para os cursos de administração conduzem à necessidade de se avaliar criticamente as experiências e posicionamentos dos executivos em relação aos aspectos sociológicos, psicológicos e mesmo doutrinários das atividades empresariais.

Em uma primeira leitura, os resultados da pesquisa enfatizam a necessidade de se adequar 0 ensino/aprendizagem de filosofia ao conteúdo das teorias de administração. Essa adequação parte da premissa que o professor de filosofia e ciências sociais possua conhecimentos básicos dos pressupostos da atuação do gestor.

Outro aspecto importante diz respeito ao conceito de que os funcionários de uma organização, atualmente, também podem ser considerados empreendedores, uma vez que, preenchem a função pela qual são definidos, ou seja, são realizadores de novas combinações de meios de produção, como define Pinchot (1989, p. 191).

\footnotetext{
Empreendedores são todos os sonhadores que realizam. Aqueles que assumem a responsabilidade pela criação de inovações de qualquer espécie dentro de uma organização. O intrapreneur pode ser criador ou inventor, mas é sempre o sonhador que concebe como transformar uma idéia em uma realidade lucrativa.
}

Nesse particular, faz-se necessário advertir que na sociedade globalizada, o significado do termo empreendedor não é apenas o "empresário" no sentido estrito do termo, não apenas os homens de negócio independentes, atualmente chamados de empreendedores, mas também os funcionários que se comprometem com o alcance dos objetivos, representado na figura 1. 


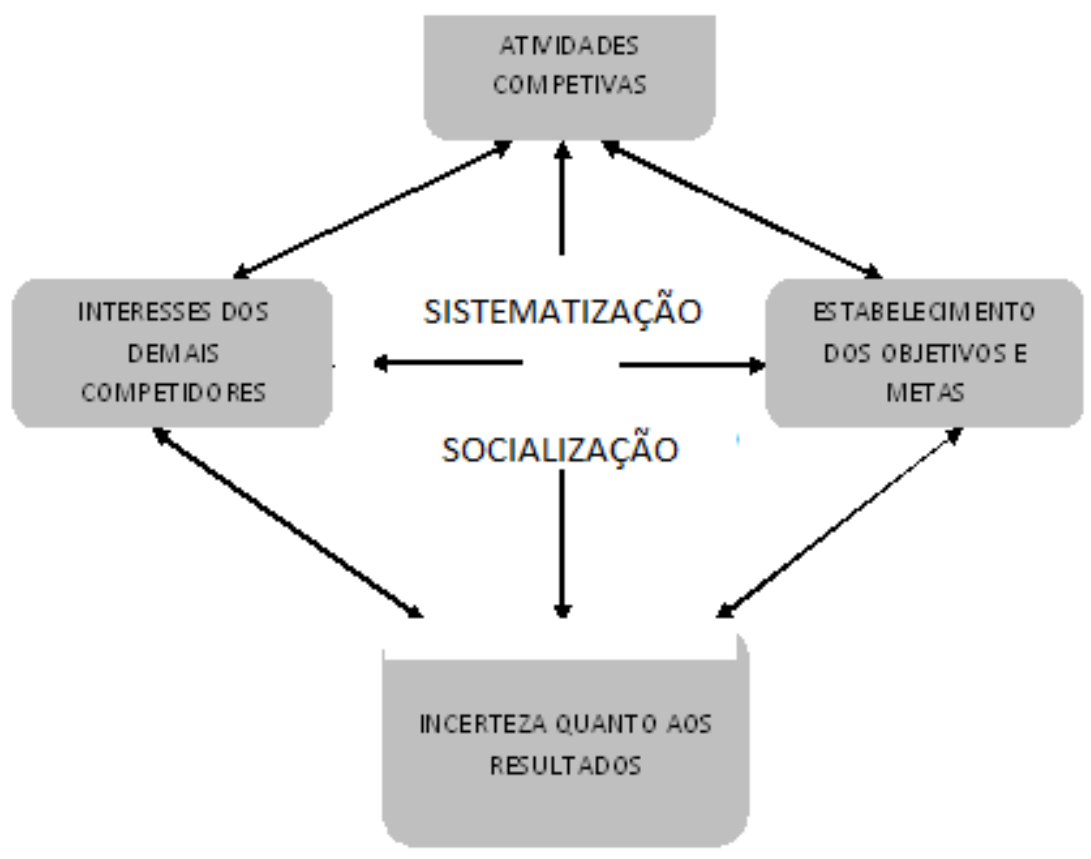

\section{Fig. 1. INTELIGÊNCIA EMPRESARIAL}

Fonte: Elaborada pelos autores

Em decorrência da junção desses três fatores (objetivos a serem alcançados, incertezas dos resultados e interesse dos competidores), a reflexão sobre os conceitos de inteligência competitiva nas ciências sociais deve ser cumulativa e crítica com o intuito de ser sistematizado e socializado para os envolvidos no processo. Essa visão ampla e pragmática do conceito de empreendedor está em consonância com a visão da AS contida no pensamento do filósofo John Dewey. Dewey (1959) desloca o foco da questão do conhecimento para o conceito de utilidade ao ressaltar que não existe uma verdade ou inverdade em si mesma, só existe uma verdade ou inverdade relativa à vida humana. O que é útil e vantajoso é verdadeiro o que é inútil ou desvantajoso é falso.

Portanto, filosoficamente, no universo das atividades competitivas, algo pode ser objetivamente verdadeiro e ao mesmo tempo subjetivamente falso, conforme o valor ou desvalor que tenha para minha vida de uma determinada comunidade, a mesma coisa pode ser verdadeira (útil) para mim e não verdadeira (inútil) para meu próximo com outros interesses.

Os exemplos citados pelos pesquisados serão enquadrados no método proposto nesse estudo (quadro 1) e analisados a partir do próximo item ("exemplos marcantes") apontam a necessidade de se dotar de ferramental teórico os educandos para um melhor entendimento das disciplinas consideradas práticas do curso.

É interessante observar que a necessidade de se adequar o conteúdo filosófico à prática empresarial para solução de problemas como ocorre na cultura oriental foi mencionado por Gabor (2001, p.223), ao citar o espanto de Edward Deming diante das diferenças entre o pensamento japonês e norteamericano sobre filosofia empresarial: "... na cultura japonesa, quando se fala de filosofia, eles a pegam e tentam trabalhar com ela como tal. Na Ford quando se fala de filosofia, a tendência desviar do assunto". 
Em consonância com essa percepção, os resultados da pesquisa indicam que a Abordagem pelos problemas $(\mathrm{ABP})$ se torna imprescindível em atividades concorrenciais, atividades nas quais, a divagação se torna contraproducente, o conhecimento de situações concretas experienciadas pelos pensadores do capitalismo contribui para se entender metodologicamente os riscos implícitos nas decisões tomadas.

\section{Exemplos Marcantes}

Os exemplos marcantes citados (respostas da questão 4 do quadro 3) serão reproduzidos nos quadros 10, 11, 12 e 13 para um melhor entendimento do conteúdo e da metodologia consideradas pertinentes pelos educandos pesquisados.

\section{Exemplo marcante 1}

A aplicabilidade dos cinco passos do método associada ao exemplo da disputa mercadológica entre duas emissoras de TV foi bastante discutida pelos alunos e professores durante o curso.

\section{Quadro 10. Aplicabilidade do Método}

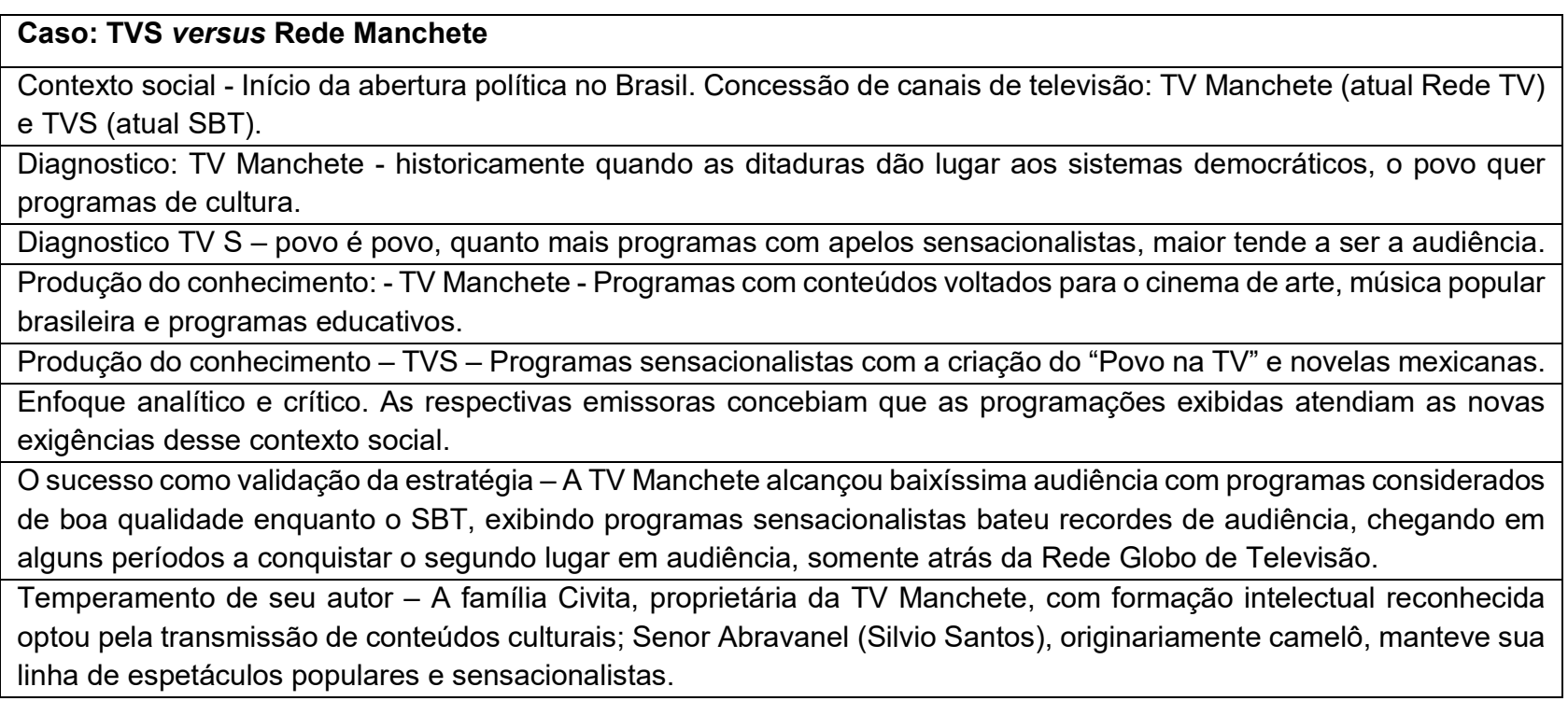

Fonte: Bazanini R; Bazanini, H.L. (2014, p. 22).

\section{Reflexões Filosóficas sobre o tema}

Em termos filosóficos, a disputa mercadológica que se estabeleceu no caso TVS versus Rede Manchete pode ser analisado a partir do referencial proposto pelo darwinismo social. O darwinismo social corresponde à luta pela sobrevivência, na qual só os mais capazes, espertos, inteligentes e precavidos conseguem sobreviver no ambiente concorrencial.

Nessa linha de raciocínio existiriam características biológicas e sociais que determinariam se uma pessoa seria superior à outra e que aquelas que se enquadrassem nesses critérios seriam as mais aptas. Geralmente, alguns padrões determinados como indícios de superioridade em um ser humano seriam o 
maior poder aquisitivo e a habilidade nas ciências humanas e exatas, decorrentes da superioridade que alguns, naturalmente, possuem em relação aos seus pares: os resultados da luta comprovam o poder do forte.

Na perspectiva dos filósofos do capitalismo os estudos de Herbert Spencer sobre o darwinismo social e a crítica de Abraham Harold Maslow dirigida ao pensamento de Peter Drucker são bastante instrutivos no sentido de contrapor o real ao ideal.

Na visão de Spencer é preciso preparar os indivíduos para serem úteis à sociedade e, ao mesmo tempo, possibilitar uma formação adequada a sua sobrevivência no âmbito do sistema capitalista. (SPENCER, 1939).

O erro no diagnóstico da TV Manchete pode ser comparado analogicamente à crítica de Maslow em relação aos princípios de Drucker.

Para Maslow, os princípios de Drucker só funcionam para uma pessoa que se encontra num nível relativamente elevado da hierarquia das necessidades, isto é, pessoas cujas necessidades mais básicas já estão satisfeitas, visto que, ignora a necessidade de selecionar o tipo certo de pessoas para que seus princípios gerenciais funcionem. Esquece, portanto, de que há muita gente no mundo para as quais esses princípios não funcionarão, gente que está doente demais para funcionar num mundo esclarecido (MASLOW, 2001).

Em termos de inteligência competitiva, a lógica não pode ser considerada como variável pertinente como propôs Zaccarelli (2000, p. 55): "Vale salientar que não existe estratégia certa, assim como não existe estratégia errada, existe estratégia que deu certo".

Portanto, o exemplo é bastante instrutivo ao referendar que o sucesso da TVS e o insucesso da TV Manchete não podem ser explicados em termos de lógica, visto que, as duas lógicas empregadas pelas respectivas emissoras podem ser consideradas pertinentes.

\section{Exemplo marcante 2}

Em relação à complementariedade entre as éticas, o exemplo da quadrilha foi relembrado por todos os educandos pesquisados.

\section{Quadro 11. Complementariedade entre as éticas}

Um exemplo extremo: uma quadrilha de salteadores. A quadrilha, na perspectiva da ética teleológica pode roubar o mundo inteiro, contudo, precisa estabelecer ações de confiança e comprometimento com os assaltantes do grupo contidas na ética deontológica e na moral da integridade para os membros continuarem unidos.

Fonte: Bazanini R; Bazanini, H.L. (2014, p. 92).

\section{Reflexões Filosóficas sobre o tema}

Em termos filosóficos, a complementariedade entre as éticas pode ser discutida a partir dos preceitos da lógica paradoxal que une os contrários num todo dialético, como por exemplo, na dialética hegeliana ilustrada no caso do senhor e do escravo. O senhor se relaciona com o escravo de forma mediata por meio da natureza, enquanto o escravo está retido nela da qual não pode abstrair-se, tronando-se dependente. $O$ 
senhor, ao contrário, tendo conseguido tal abstração, dominou a natureza e, consequentemente o escravo. Entretanto, o senhor só pode exercer sua dominação sobre o escravo, se este curvar-se às suas ordens e executar os trabalhos exigidos por ele (HEGEL, 1992).

Na perspectiva dos filósofos do capitalismo, o conceito de "mão invisível do mercado" proposto por Adam Smith explica essa dialética paradoxal no mercado. Para Smith (2003), "a mão invisível" simboliza o verdadeiro orquestrador da harmonia social presente no livre mercado, uma vez que, o auto interesse e egoísmo que podem ser considerados procedimentos imorais transformam-se em elementos altamente desejáveis ao trazer o progresso e o desenvolvimento econômico e social, portanto, responsáveis pela riqueza das nações. Essas assertivas constituem os primeiros fundamentos filosóficos do liberalismo econômico.

\section{Exemplo marcante 3}

Outro exemplo marcante citado pelos educandos se refere ao entendimento das ações consideradas legítimas nas relações que se estabelecem entre a organização e a comunidade na qual a empresa está inserida.

\section{Quadro 12. Relações da empresa com a comunidade}

\begin{tabular}{|l|l|}
\hline $\begin{array}{l}\text { Doutrina da Responsabilidade Social } \\
\text { As empresas são depositárias de recursos }\end{array}$ & $\begin{array}{l}\text { Doutrina do Interesse do Acionista } \\
\text { A responsabilidade primária da empresa é defender o interesse de } \\
\text { seus acionistas. }\end{array}$ \\
$\begin{array}{l}\text { As empresas existem com a autorização da } \\
\text { sociedade }\end{array}$ & $\begin{array}{l}\text { Defendendo o interesse do acionista, a empresa faz o que sabe } \\
\text { fazer melhor e beneficia a sociedade pela produção de riquezas. }\end{array}$ \\
$\begin{array}{l}\text { As empresas tem a obrigação de agir segundo } \\
\text { os interesses da soociedade }\end{array}$ & \begin{tabular}{l} 
âmbito das organizações de caridade e do governo. \\
\hline
\end{tabular}
\end{tabular}

Fonte: Bazanini (2010, p. 99).

\section{Reflexões Filosóficas sobre o tema}

Em termos filosóficos, o debate que se estabelece nas relações da empresa com a comunidade propõe a discussão sobre os valores determinantes que contribuem para a dignidade do ser humano. Nessa perspectiva, é possível questionar: os executivos devem optar pela razão instrumental que coloca o lucro acima de tudo, o relacionamento competitivo com o mercado na relação ganha-perde e, para isso é preciso possuir interesses pela arte da guerra, ou pela razão humanista que coloca o homem acima de tudo, o relacionamento colaborativo com o mercado na relação ganha-ganha e, para isso é preciso se interessar pelo bem estar de todos?

Em nossa contemporaneidade, essas duas posturas, por vezes convivem, ora colaborativamente, ora litigiosamente, como pode ser observada na relação das empresas associadas ao Instituto Ethos de Responsabilidade Social, e, como na dialética do senhor e o escravo, não pode haver vencedor e perdedor 
entre os defensores dessas duas posturas, porque isso causaria a morte de ambos e impediria que o processo de conhecimento progredisse (HEGEL, 1992).

Desse modo, os exemplos citados pelos pesquisados apontam a necessidade de dotar a filosofia de conteúdos e metodologia relacionadas à resolução de problemas como ferramental teórico dos educandos para um melhor entendimento das disciplinas consideradas práticas do curso.

\section{Exemplo marcante 4}

$\mathrm{Na}$ perspectiva dos filósofos do capitalismo, a queixa apresentada por Frederick Taylor em seu depoimento a comissão da Câmara em 1912, sobre a Administração Cientifica,advertindo que sua teoria foi interpretada de forma unilateral constitui também um excelente exemplo da complementariedade entre a visão da Doutrina do Interesse do Acionista e Doutrina da Responsabilidade Social.

\section{Quadro 13. Reprodução do depoimento de Frederick Taylor}

A Administração Científica não é nenhum artifício para o aumento da eficiência, ou sequer um artifício para conseguir eficiência.

Não é um novo sistema de custeio; não é um novo esquema de remuneração; não é um sistema de pagamento por tarefa; não é um sistema de prêmios; não é um sistema de bonificações; não é um esquema de remuneração de empregados; não é cronometrar o trabalho de um homem e depois anotar algo numa prancheta; não é estudo de tempos; não é estudo de movimentos ou análise dos movimentos dos operários; não é a impressão e imposição de uma tonelada ou duas de formulários aos trabalhadores, dizendo-se: "Está aqui o sistema de vocês; usem-no". Não é a divisão de trabalho de contramestre ou contra mestria funcional; não é qualquer um dos dispositivos que a média das pessoas logo pensa ser, quando se fala em administração científica...".

(...) Agora, em sua essência, a administração cientifica envolve uma revolução mental completa por parte do trabalhador envolvido em qualquer estabelecimento ou atividade particular - uma revolução mental completa de parte desses homens em relação às suas obrigações para com seu trabalho, seus colegas e seus empregadores. E envolve a revolução mental igualmente completa por parte dos indivíduos do lado da administração - o contramestre, o superintendente, o proprietário da empresa, o conselho de administração -, uma revolução mental completa de sua parte em relação às suas obrigações para com seus colegas na administração, seus empregados e todos os seus problemas cotidianos.

A grande revolução mental que ocorre na atitude mental das duas partes sob a administração científica é representada pelo fato de que os lados tiram seus olhos da divisão do excedente, como questão dominante, e voltam conjuntamente suas atenções para o aumento do tamanho do excedente, até que este se torne tão grande que passe a ser desnecessário brigar sobre como deve ser dividido. Começam a perceber que quando parar de brigar uns com os outros, e em vez disso lutam ombro a ombro na mesma direção, o tamanho do excedente criado por seus esforços, o conjunto torna-se realmente assombroso. Ambos os lados reconhecem que quando substituem o antagonismo e o conflito por cooperação amigável e solidariedade tornam-se capazes, em conjunto, de aumentar tanto esse excedente que passa a haver amplo espaço para um substancial aumento de salários para o trabalhador e aumento igualmente significativo dos lucros do industrial.

Fonte: Bazanini (2007, p. 2010) extraído de Taylor (1912). 
Em suma, Frederick Taylor, em sua justificativa busca desfazer o conceito de que em sua teoria a produtividade e a preocupação com a compressão do tempo são enfatizadas em detrimento da qualidade de vida dos trabalhadores e das questões de ética e de responsabilidade social.

Assim, o debate filosófico sobre as estratégias presentes no ensino/ aprendizagem de filosofia com o emprego ABP na perspectiva da visão empreendedora, permite resgatar as teorias propostas no mundo dos negócios para se discutir criticamente sua pertinência atual.

\section{CONSIDERAÇÕES FINAIS}

Como vimos, William James em suas conferências sobre pragmatismo fez questão de reiterar que o pragmatismo é "um novo nome para os velhos modos de pensar". O pragmatismo guarda em sua essência a própria designação que os antigos atribuem à filosofia. Ou seja, uma atividade intelectual altamente comprometida com os temas e os problemas concretos da humanidade.

Nessa perspectiva, a proposta da pesquisa buscou comparar a visão da filosofia, em seu sentido amplo e problematizador, com a visão dos filósofos do capitalismo, cujo paradigma, acentuadamente pragmático, volta-se para a organização, o lucro, a competência e a competitividade.

Com base nos resultados da pesquisa é possível conceber que, por razões práticas e por razões históricas, os cursos de administração deveriam ser, por excelência, multidisciplinares, visto que, o trabalho numa organização exige dos executivos conhecimentos, habilidades e atitudes relacionadas às diversas áreas de conhecimento.

Historicamente, a sociologia e a psicologia se tornaram independentes da filosofia como ramos do conhecimento a partir de meados do século XIX e, basta nos reportamos aos primeiros teóricos do pensamento administrativo, para constatar como as ciências sociais, desde seus primórdios, foram objeto de estudo desses pensadores.

- Frederick Taylor e Henry Fayol, oriundos da engenharia, passaram pela psicologia e pela sociologia organizacional;

- Elton Mayo, Amitai Etzioni, Douglas McGregor, Herbert Simon foram fortemente influenciados pelos conceitos das ciências humanas (filosofia, antropologia) e também pela psicologia e sociologia organizacional;

- Mary Follet e Chester Barnard fundamentaram suas reflexões nos pressupostos do pensamento de Bertalanffy (1975) que considerava que a ciência tratava de maneira fragmentada muitos problemas que exigiam uma abordagem mais ampla e holística e na sociologia organizacional, particularmente os trabalhos de Woodward $(1971,1984)$ e Thompson (1967).

Em consonância com essa percepção, os resultados da pesquisa indicam que a Aprendizagem Baseada em problemas (ABP) se torna imprescindível em atividades concorrenciais, atividades nas quais, a aprendizagem mecânica, repetitiva e memorística e a divagação se tornam contraproducentes.

Ocorre que a metodologia e os conteúdos ministrados no ensino tradicional nas ciências sociais aplicadas mantém a contradição entre educador-educando, por separar efetivamente o processo de produção 
do conhecimento das exigências do contexto social ao distinguir a ação do educador em dois momentos: o primeiro, o educador em sua biblioteca adquire os conhecimentos, e no segundo, diante da classe, apresenta aos educandos os resultados de suas leituras, cabendo a esses apenas arquivar o que ouviram ou copiaram.

Essa concepção desconhece que a Filosofia é uma experiência do pensamento humano que convida adentrar ao mundo do conhecimento e, com isso, oferece uma oportunidade excepcional de se apreender a realidade, transformando-a de forma a torná-la melhor para o convívio humano e a pertinência ou não para se avaliar o valor do pensamento filosófico está no debate sobre a maneira correta de se colocar um problema.

Diante disso, a necessidade de alfabetização metodológica e a visão sintética das abordagens Baseadas em Problemas ( $A B P$ ) podem se constituir em recursos imprescindíveis para se entender a pertinência do pensamento filosófico por meio de reflexões temáticas como ocorreu nesse estudo.

A experiência realizada em sala de aula acompanhada da pesquisa de campo propiciou a obtenção de respostas incorporadas numa visão sistêmica, ao unir a racionalidade dos procedimentos (diagnosticar, fixar objetivos, propor metas, elaborar programas, etc.) tendo como base a cultura de determinada sociedade (hábitos, costumes, script de vida, etc.).

Por um lado, a adoção da metodologia da pesquisa-ação permite à percepção do contexto, a identificação do problema, a solução proposta passa necessariamente pela racionalidade do discurso, visão holística e entendimento pragmático da atividade executiva, por outro, permite também a releitura crítica dos filósofos do capitalismo referente aos atributos de egoísmo e altruísmo, competição e concorrência, motivação e produtividade, conceitos esses, essenciais na formação dos futuros profissionais da administração.

Dentre as principais limitações da pesquisa evidencia-se a amostra constituída de três professores e quarenta alunos. Diante disso, pode-se inferir que, em amostras maiores, certamente, algumas dificuldades, talvez sejam evidentes: os educandos, acostumados a "receber" passivamente as informações, diante de situações em que são exigidas maior atividade, trabalho e esforço tendem a mostrarem-se, inicialmente, resistentes ao novo método, também, decorrente do hábito no ensino tradicional estar baseado na memorização, alguns professores tendem a manifestar certa relutância na aplicação do método; principalmente pelo custo demandado na elaboração dos textos dos problemas, visto que, para isso requerse certa dose de criatividade.

Enfim, o ensino-aprendizagem de filosofia da administração relacionada à Abordagem pelos Problemas $(A B P)$ constitui uma proposta aberta sujeita às diferentes possibilidades e direcionamentos e pode ser um caminho possível para a formação de um administrador que, ao mesmo tempo, possua sólida formação humanística, também, esteja apto para dominar as ações e tecnologias empresariais num ambiente de contínuas transformações.

Como dito anteriormente, para futuras pesquisas sugere-se a aplicação dessa metodologia no ensinoaprendizagem da disciplina filosofia nos cursos de administração com amostras mais amplas e representativas. 


\section{REFERÊNCIAS}

ALMEIDA, M.E.B.; ALONSO, M. (orgs). Tecnologias na Formação e na Gestão Escolar. São Paulo, Avercamp, 2007.

BARBIER, R. A pesquisa-ação. Brasília: Plano, 2002.

BARNARD, C. I.The Functions of the Executive. Harward, University Press, 1968.

BARRAWS, H. S.; TAMBLYN, R, M. Problem-Based Learning: an approach to medical education. New York, USA: Springer, 1980. v. 1. Disponível em: <http://books.google.com.br/books ?hl=pt-BR\&lr=\&id=9u-DJuQq2UC\&oi 6g0bfFEyyTZEi ToLe1RU\#v=onepage\&q=. Acesso em: 13 abr. 2014.

BAZANINI, R. Filosofia e Evolução das Ideias Sociais: visão critica das ideologias no mundo dos negócios. São Paulo, Plêiade, 2010

BAZANINI, R. The teaching of Philosophy as a Human Existential Procedure. The Bazanini Method in teaching of Philosophy. Philosophy applied to the administration. Paper aprovado no Global Congress on Engineering and Techonology Education.GCETE 2005.

BAZANINI, R. Visão Filosófica das estratégias em administração: Há controvérsias e conveniências. São Paulo, Plêiade, 2007.

BAZANINI. R; BAZANINI, H.L. Filosofia e Ética nas Ciências Sociais Aplicadas. Estratégias e Lógica da Inteligência Competitiva. São Paulo, Plêiade, 2014.

BERBEL, N. A.. A problematização e a aprendizagem baseada em problemas: diferentes termos ou diferentes caminhos? Interface - Comunicação, Saúde, Educação.n.2, p. 139-154, fev.1998.

BERTALANFFY, L. Von. Teoria geral dos sistemas. Petrópolis: Editora Vozes, 1975.

BUFREM, L. S.; SAKAKIMA, A. M. O ensino, a pesquisa e aprendizagem baseada em problemas. Transformação: Campinas, v. 15, n. 3, p. 351-361, set./dez. 2003. Disponível em: <http://www.brapci.ufpr.br/download.php?dd0=15260>. Acesso em: 3 mai. 2013.

CASTELLS, Manuel. A sociedade em rede. 8. ed. São Paulo: Paz e Terra, 2005.

CLOVER, V; BALSLEY, H. Business Research Methods. Columbus, Grid Incorporation, 1974.

DEMING, W.E., Qualidade. A Revolução na Administração, Marques Saraiva, 1997.

DEWEY, J. Liberalismo, Liberdade e Cultura. Sã Paulo, Companhia Editora Nacional, 1959.

DRUCKER, P. Sociedade pós-capitalista. São Paulo, Pioneira, 1993.

DUTRA, J.S; FLEURY, T.L; RUAS, R. Competências: conceitos, métodos e experiências. São Paulo, Atlas, 2008.

EMORY, C. W. Business Research Methods. Homewood, Richard. D. Irwin, 1980.

FAYOL, H. Administração Industrial e Geral. 9ed. São Paulo, Atlas, 1987.

FLICK, U. Introdução à Pesquisa Qualitativa. 3ed. Artmed, Porto Alegre, Rio Grande do Sul, 2009.

FOLLET, M. P. Dynamic Administration: the collected papers of Mary Parker Follet. Edited by Henry C. Metcalf an L. Urwic.New York/London, Harper\&Brother Publsihers, s/d.

GABOR, A. Os Filósofos do Capitalismo: A genialidade dos homens que construíram o mundo dos negócios. Rio de Janeiro, Campus, 2001.

GIGLIO, E. M.; HERNANDES, J.L.G. Discussões sobre a Metodologia de Pesquisa sobre Redes de Negócio Presentes numa Amostra de Produção Científica Brasileira e Proposta de um Modelo Orientador, RBGN-Revista Brasileira de Gestão de Negócios, v.14, n.42, 2012, pp. 78-101.

GODOY, A.S. Introdução à pesquisa qualitativa e suas possibilidades. RAE-Revista de Administração de Empresas, v.35, n.2, 1995, pp.57-63.

HEGEL. G.W.F. Fenomenologia do Espírito, Rio de Janeiro, Vozes, 1992.

JAMES, W. Pragmatismo e outros textos. $2^{\mathrm{a}}$ ed. São Paulo, Abril Cultural, 1985.

LAWLER, E. Doing Research that is Useful for Theory and Practice. San Francisco, Jossey Bass Inc., Publishers, 1985.

LEMOS, A. Cibercultura, tecnologia e vida social na cultura contemporânea. Porto Alegre, Sulina, 2002.

LOPES, P.C. Reflexões sobre as bases de formação do administrador profissional no ensino de graduação. In: ENCONTRO DA ANPAD, 26, 2001, Salvador. Anais... Rio de Janeiro: ANPAD, 2002, p. 1-16.

MASETO, M. T. Competências Pedagógicas do Professor Universitário. 2. ed. São Paulo: Summus, 2012.

MASLOW, A.H.Eupsychian Management. Nova York, Hardcover, 2001. 
MAYO, E. The Human Problems of Industrial Civilization. New York, The Macmillan Company, 1933.

MCGREGOR, D. O lado humano da empresa. São Paulo: Martins Fontes, 1992.

PFEFFER, J.; FONG, C.T. The business school "business": some lessons from the US experience. Journal of Management Studies, v. 41, v.8, 1501-1520, 2004.

PINCHOT, Gifford. Intrapreneuring: Por que você não precisa deixar a empresa para tornar-se um empreendedor. São Paulo, Habra, 1989.

PLUTARCO, F.F.; GRADVOHL, R. F. Competência dos professores de administração: a visão dos alunos de cursos de Graduação. In; ENCONTRO ANUAL DA ANPAD, 34., 2010, Rio de Janeiro. Anais ... Rio de Janeiro: ANPAD, 2010, p. 1-16.

PRADO DE MENDONÇA, E. O Mundo Precisa de Filosofia. Rio de Janeiro, Agir, 1984.

PRETTO, N. L.; RICCIO, N. C. R. A formação continuada de professores universitários e as tecnologias digitais. Educar, Curitiba, n. 37, p. 153-169, maio/ago. 2010.

RAMOS, K. M. Reconfigurar a Profissionalidade Docente Universitária: um olhar sobre ações de atualização pedagógico-didática. Porto: Universidade do Porto, 2010.

RIBEIRO, L. R. Aprendizagem Baseada em Problemas (PBL): uma experiência no ensino superior. São Carlos: Eufsc, 2008.

RIGBY, P. H. Conceptual Foundations of Business Research. New York. John Wiley and Sons, Inc, 1965.

SAMPIERI, R.H.; COLLADO, C.F.; LUCIO, P.B. Metodologia de La Investigación. México, McGraw-Hill, 1991.

SPENCER, H. Do Progresso: sua Lei e sua Causa. Lisboa, Editorial Inquérito, 1939.

SMITH, A. A Riqueza das Nações. São Paulo, Martins Fontes, 1ª. ed., 2003.

TAYLOR, F. W. Princípios de Administração Científica. 8 ed. São Paulo, Atlas, 1990.

TAYLOR, F. W. Testimony Before The Special House Committee (1912).Disponível em www.cbo.gov/publications/collections/prescriptiondrugs.cfm. Acesso em 12/07/2014.

THOMPSON, J. D. Organizatíons in acdion. Nova York: Mc Graw·Hill, 1967.

VEEN, W \& VRAKKING, B. (2009). Homo zappiens: educando na era digital. Porto Alegre, Artmed, 2009.

VERGARA S.C. A formação do administrador como requisito para o exercício da função gerencial no Brasil. In; ENCONTRO ANUAL DA ANPAD, 31., 2007, RIO DE Janeiro. Anais ... Rio de Janeiro: ANPAD, 2007, p. 1-15.

WOODWARD, J. Management and Technology in Pugh, D. S. Organization Theory, Middlesex, England: Penguin, 1971, 1984.

YIN, R.K. (2010), Estudo de Caso: Planejamento e Métodos. 4 ed. Porto Alegre, Bookman,2010.

ZACARELLI, S.B. Estratégia e Sucesso nas Empresas. São Paulo, Saraiva, 2000.. 